\title{
Controle de Modelos Robóticos por Meio de Gestos Naturais
}

\author{
Paulo Henrique R. de Souza ${ }^{1}$, Welerson Augusto L. de Jesus Melo ${ }^{1}$, Icaro \\ Meneses F. de Santana ${ }^{2}$, Nara Strappa F. Doria ${ }^{3}$, Leila Buarque C. de \\ Matos $^{3}$
}

${ }^{1}$ Discente do Curso Técnico Integrado Informática ao Ensino Médio, ${ }^{2}$ Discente do Curso Técnico Integrado Eletrônica ao Ensino Médio, ${ }^{3}$ Docente de Eletrônica

${ }^{123}$ Instituto Federal de Educação, Ciência, Tecnologia de Sergipe (IFS)

Av. Eng. Gentil Tavares, 1166 - Getúlio Vargas, Aracaju - SE, 49055-260

paulohenriqueifs@live.com, welerson.a.melo@gmail.com, icaro.santana.ifs@

gmail.com, narastrappa@gmail.com, leila.buarque.couto.matos@gmail.com

Abstract: This article describes the creation of new control methods of robotics models through a human-robot interface based on natural gestures, integrating the Arduino and Processing programmable platforms to Kinect and Bluetooth, enabling any person to control remotely the robot using body movements.

Resumo: Este artigo descreve a criação de novos métodos de controle de modelos robóticos através de uma interface humano-robô baseada em gestos naturais, integrando a plataforma programável Arduino e Processing ao Bluetooth e Kinect, possibilitando a qualquer pessoa controlar um robô remotamente usando movimentos do corpo.

\section{Introdução}

Com a crescente popularização dos modos de interação homem-máquina através da interface natural, foi notável a necessidade de um olhar diferente para essa área de modo que ela possa ser aproveitada ao máximo. O Kinect surge então como grande precursor dessa interface, que segundo Jain et al. (2011), é a forma que permite que os usuários interajam com os computadores da maneira que interagem com o mundo.

Nesse contexto, propõe-se criar novas formas de controle de robôs a partir da interface humano-robô baseada em gestos naturais, integrando a plataforma programável Arduino ao Kinect, possibilitando a qualquer pessoa controlar um robô remotamente usando movimentos comuns do corpo. O restante deste artigo está estruturado como segue: na Seção 2, é apresentado o referencial teórico, enquanto na Seção 3 é resumida a proposta, os materiais utilizados e a implementação. Os resultados obtidos são apresentados na Seção 4 e, por último, na Seção 5 são feitas algumas considerações finais.

\section{Referencial Teórico}

No mundo da tecnologia há diversos tipos de integração homem-máquina, dentre as quais se podem citar a Interface de Linha de Comando (CLI), a Interface Gráfica (GUI) e a Interface Natural (NUI). Esta última é baseada em comandos realizados pelo corpo humano através de algum objeto ou diretamente pela captação dos gestos. A Interface 
Natural Humano-Robô é uma importante função nos sistemas de operação robóticos (Kun Qian, et al., 2013), pois aumenta a interação entre o homem e a máquina.

Pensando na abrangência de uma nova tecnologia com Interface Natural, a Microsoft desenvolveu o dispositivo Kinect. Este dispositivo tem mudado a forma como as pessoas integram-se à tecnologia, e seu impacto vai além da indústria de games, com um baixo custo e fácil aquisição. Segundo Zhengyou Zhang (2012) muitas pesquisas vêm sendo realizadas na área da ciência e engenharia, automação (Moreno, 2014) e saúde.

\section{Aplicação}

A partir do exposto, viu-se a oportunidade de conectar a tecnologia do Kinect à robótica utilizando comunicação sem fio, a fim de criar novos métodos remotos de controle de robôs. Para o projeto, foi desenvolvido um robô móvel com rodas que possuía dois motores DC, um chassi, um Arduino Uno, Chip L293D, Módulo Bluetooth e baterias. Além disso, foi criado um braço robótico de ferro com três servomotores simulando os movimentos do ombro, cotovelo e mão humana. No que se refere à Programação Orientada a Objetos, optou-se pelo uso da IDE Processing.

Quatro métodos de controle foram criados para o sistema, sendo um pelo teclado e os outros três pelo Kinect, que detecta automaticamente o corpo do usuário se este estiver devidamente posicionado à frente do dispositivo, tanto em pé como sentado.

No Método 0, o usuário utiliza o teclado para movimentar o robô. O Método 1 capta o ponto mais próximo da tela para mover os motores sem variação de aceleração (Ribeiro et al., 2013). Já o Método 2 utiliza a angulação formada entre os ombros e cotovelos para mover os motores com variação de aceleração (Correa, Marcos Vinicius, 2014). O Método 3, o novo modo criado, simula um volante, através da angulação formada por uma linha imaginária entre as mãos e a distância das mãos ao corpo para mover os motores com variação de aceleração. Os métodos 0 e 2 são utilizados tanto no robô com rodas como no braço robótico.

Enfim, os dados gerados a partir da movimentação do usuário são tratados e transformados de acordo com a programação do método utilizado e enviados em tempo real e via Bluetooth ao Arduino, que lê os dados e escreve as potências de cada motor de acordo com as entradas. A diferença entre o tempo de resposta nos diferentes métodos foi desconsiderada neste trabalho por ser um valor muito pequeno.

\subsection{Implementação}

Integrando as bibliotecas open source OpenNI e Nite2.0, (Melgar e Diez, 2012) foi possível detectar o posicionamento dos membros e retornar as coordenadas no campo 3D dos pés, joelhos, mãos, cotovelos e ombros. Os dados das coordenadas que podem vir com ruídos são tratados com média móvel e ligados para criar a imagem do esqueleto do humano que é sobreposta à sua imagem real. Precisou-se detectar o estado da mão do usuário (aberta ou fechada) e então foi implementado o algoritmo Flood Fill que age pelas conexões de pontos em um grafo (Felix e Steven Halim, 2012).

No Método 3, para realizar o movimento de curva com o robô com rodas, obteve-se em relação ao eixo X (horizontal) e ao eixo Y (vertical) a diferença entre as duas mãos e assim foi calculado o coeficiente angular da reta imaginária formada entre 
elas definindo para qual lado o robô deve virar e a aceleração centrípeta nas curvas. Já para o braço robótico utilizou-se a programação do Método 2 adaptada para responder o mais próximo possível da posição real do braço do usuário.

\section{Resultados}

Foram realizados testes de laboratório com alguns voluntários a fim de melhorar a aplicação, avaliar a aceitação e gerar gráficos. A Figura 1 mostra a tela com os dados de potência linear (centro da tela), a proporção entre as potências nos motores (canto esquerdo da tela) e o estado das mãos, necessário para estar no controle do sistema.

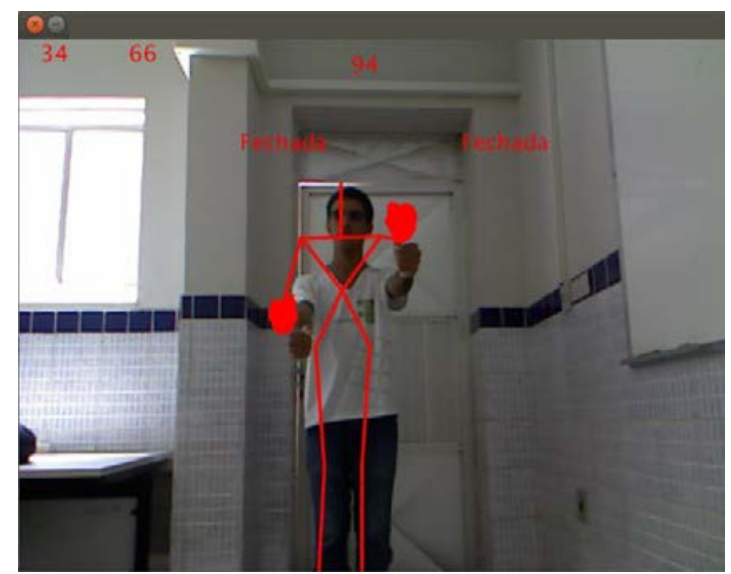

Figura 1. Voluntário utilizando o Sistema no Método 3.

Tomando o Método 0 e o Método 3 no robô com rodas, foram gerados gráficos que mostram a diferença entre os dois métodos numa trajetória que se definiu por variações em uma pista que apresentava curvas para a direita e esquerda. A pista possuía dois metros de comprimento por um metro de largura. Os dados apresentados nos gráficos fazem referência à proporção entre os motores, indicando qual lado está recebendo a maior potência. Ou seja, quanto mais baixo maior a curva para a direita.
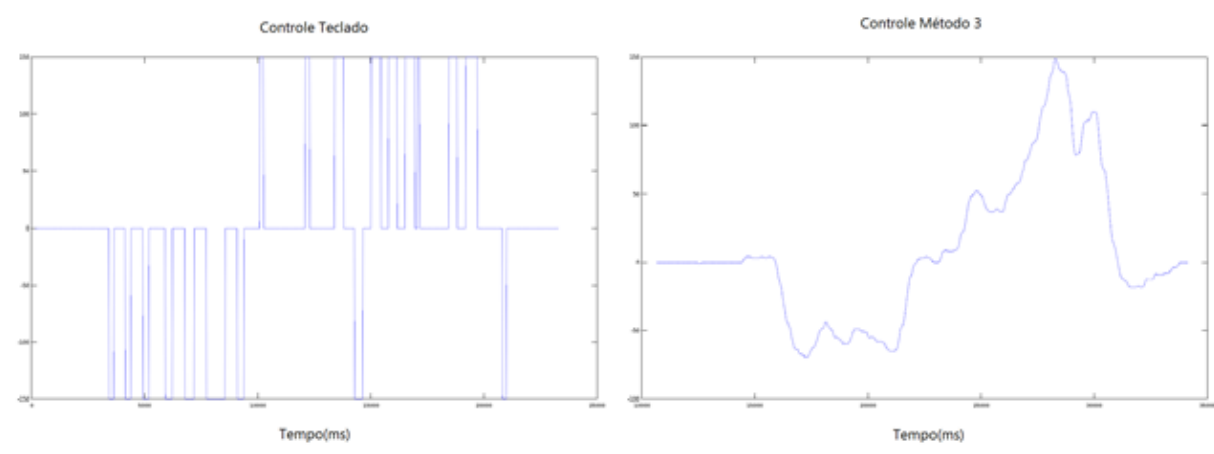

Figura 2. Gráficos dos métodos de controle - Robô com rodas

O gráfico da Figura 2, gerado a partir de amostras, apresenta no eixo horizontal os dados de tempo em milissegundos e no eixo vertical a diferença proporcional de potência entre os motores. Pode-se perceber a maior suavização do movimento com o Kinect. Vemos de modo semelhante nos gráficos da Figura 3 os resultados do Método 0 utilizando o teclado e do Método 2 utilizando o Kinect para controle do braço robótico. A tarefa foi levar o Braço Robótico até o centro de um pneu pequeno, estendê-lo e arremessá-lo para o lado ao fechar a mão. O pneu distava vinte centímetros em relação à base do Braço Robótico e seis centímetros de altura. 


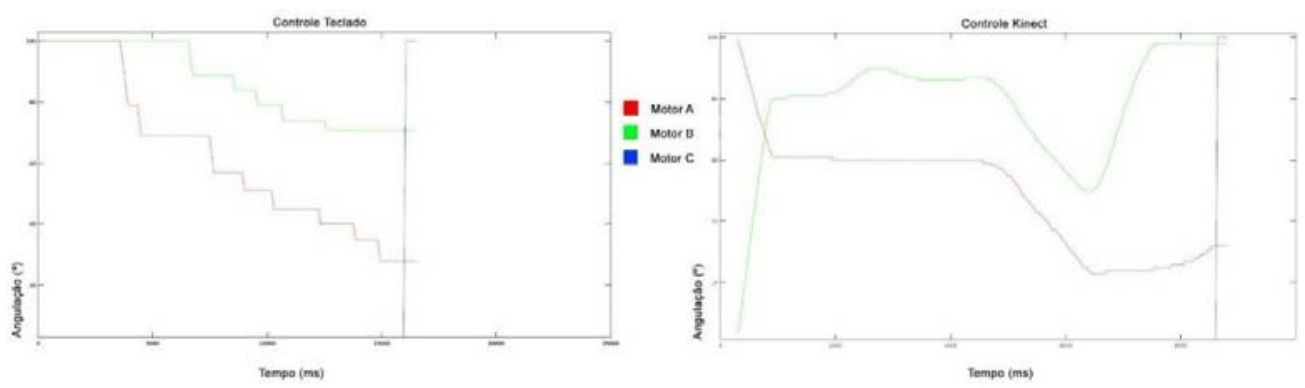

Figura 3. Gráficos dos métodos de controle - Braço Robótico

No gráfico acima, o Motor A representa a articulação do ombro, o Motor B a articulação do cotovelo; o Motor C, a abertura da mão. É possível observar a partir das amostras que o método utilizando o Kinect terminou a tarefa aproximadamente duas vezes mais rápido, além de possuir maior suavização dos movimentos articulares e um controle mais intuitivo. Os resultados podem ser vistos nos vídeos: https://youtu.be/4iPneecyNJ4 e https://youtu.be/6AezSTYSE00.

\section{Conclusão e trabalhos futuros}

Tendo em vista que a Interface Natural aplicada à robótica tem um grande potencial de desenvolvimento no mundo, o projeto utilizou uma metodologia simples para conectar tecnologias e alcançar o resultado desejado. Foi possível controlar de forma remota um robô com rodas e um braço robótico utilizando o próprio corpo, demonstrando maior eficácia no principal método proposto em relação aos métodos já existentes implementados. Futuramente, visa-se o estudo de técnicas de filtragem e suavização de movimentos para os motores, sendo que a partir dos gráficos pôde-se perceber pequenos erros e oscilações indesejadas devido à baixa qualidade dos dados recebidos do Kinect.

\section{Referências}

CORREA, M. V. C. (2014). "Controle de robôs móveis utilizando o Kinect”. Escola de Engenharia de São Carlos da Universidade de São Paulo.

Halim, S., Halim F. (2012). "Competitive Programming 2". Lulu Press.

Jain, J., Lund, A., Wixon, D. (2011). The future of Natural User Interface. In: CHI '11 Extended Abstracts on Human Factors in Computing Systems, pages 211-214.

Melgar, E., Diez, C. (2012). "Arduino and Kinect Projects: Design, Blow Their Minds." Technology in Action.

Moreno, R. J. (2014). "Tracking Humano mediante Kinect para control de robots". Universidad Autónoma de Colombia.

Niu, J., Quian, R. and Yang, H. (2013). "Developing a Gesture Based Remote HumanRobot Interaction System Using Kinect", In: "International Journal of Smart Home”.

Ribeiro, L. C., Farias, Farias, A.B., Amaral, E.M.A. (2013) "Sistema De Controle De uma Plataforma Robótica Experimental Baseado em Visão Computacional Utilizando Kinect", In: "Mostra Nacional de Robótica".

Zhang, Z. (2012) "Microsoft Kinect Sensor and Its Effect", In: "IEEE Multimedia", pages 4-10. 